J. Asiat. Soc. Bangladesh, Sci. 40(2): 187-196, December 2014

\title{
PROXIMATE DETERMINANTS OF PHYSICAL FITNESS LEVEL OF REPRODUCTIVE WOMEN IN BANGLADESH
}

\author{
PAPRI SHANCHITA ROY ${ }^{1}$ AND MD. NAZRUL ISLAM ${ }^{2}$ \\ Department of Business Administration, Stamford University, Dhaka, Bangladesh \\ ${ }^{2}$ Department of Statistics, Shahjalal University of Science and Technology, Sylhet, Bangladesh
}

\begin{abstract}
Results of the analysis revealed that women's age, place of residence, education, working status, occupation and wealth index were the significant proximate determinants of their physical fitness level. The prevalence of underweight decreased and the prevalence of overweight increased with the increase in the age of reproductive women. Fifty-nine percent of adolescent women (aged 15-19 years) were underweight. The level of education was negatively associated with being underweight but positively associated with being overweight or obese. Of 3,472 illiterate women, about 59 percent were underweight, and of 847 higher-educated women, $37 \%$ were overweight. The poor women were three times [odds ratio $(\mathrm{OR})=3.22$, 95\% confidence interval $(\mathrm{CI}$ : 2.73-3.81)] more likely to have underweight or malnutrition compared to women of high socioeconomic status, and rural women were slightly $(\mathrm{OR}=1.10,95 \% \mathrm{CI}: 1.00$ 1.22) more likely to have underweight or malnutrition than those of urban. The housewives or unemployed women, were almost two times $(\mathrm{OR}=1.55,95 \% \mathrm{CI}$ : 1.33 1.80) more likely of being overweight or obese than the working women. The findings of this macro-level study of public-health issue will help the Government and planners to take sustainable policies for improving the reproductive women's health.
\end{abstract}

Key words: Reproductive health, Physical fitness, Proximate determinants, Body mass index, Multinomial logistic regression analysis, Bangladesh

\section{Introduction}

In developing countries, ensuring sound health of reproductive women is a major public health problem. Due to relatively low status and lack of access to reproductive health and family-planning services, maternal mortality and other risks of physical problems are unacceptably high among them. Evidence indicates that conditions being underweight or overweight can exist in close proximity. Such conditions could be linked with different environmental, behavioural and individual risk factors. An increasing trend of overweight and obesity, in combination with a high prevalence of underweight, is common in many developing countries, including Bangladesh. Globally, about 1.6 billion adults are overweight, of which at least 400 million are obese (WHO 2006). The study on the determinants of physical fitness level of reproductive women is very important to find out

\footnotetext{
${ }^{1}$ Corresponding author: Email: papri_stat@yahoo.com
} 
the segments where their fitness level is satisfactory or not. It is also essential to identify the dissatisfactory segments of population where special programmes and interventions are necessary. Using data from the BDHS 2004, Khan and Kraemer (2009) have studied the factors associated with being underweight, overweight, and obese among evermarried non-pregnant urban women in Bangladesh. They have applied bivariate and multinomial logistic regression analyses in their study. Findings of the study have showed that suitable interventions are needed to reduce the prevalence of underweight and overweight among these women. The study has also revealed the incidence of being overweight and obese is gradually increasing among ever married non-pregnant women although the prevalence of being underweight decreases gradually.

The Body Mass Index (BMI) is a good indicator of nutritional status in a population. In underdeveloped countries like Bangladesh, this indicator provides a method that can assist intervention to help eradicate many preventable diseases. Hossain et al. (2012) have reported on the changes in BMI of married Bangladeshi women born in the past three decades and its association with the socio-demographic factors. They have found that the proportion of underweight females who were born during the last 20 years of the study period (1972-1992) has been increasing. The BMI has increased with the increase in age, education level of the woman and her husband, wealth index, age at first marriage and age at first delivery and decreased with the rising number of ever-born children.

Using data on height and weight of 3,428 non-smoking healthy adults of Delhi in India, Chhabra and Chhabra (2007) have attempted to find out the distribution and determinants of BMI of the person. They have found that the prevalence of underweight is higher in rural areas and among the lower-income group while overweight and obesity are more common among urban residents, women, and the higher-income group.

Chiu et al. (2000) have conducted a prospective cross-sectional study on height, weight, and BMI of elderly people in Taiwan using data from a population-based geriatric survey. They have observed the disease pattern, health status, and lifestyle of the community people aged 65 years and over. It has been found that the elderly men are taller and heavier than the elderly women although the women have a higher value of mean BMI.

Subramanian et al. (2009) have investigated the coexistence of underweight and overweight and found that with rapid economic growth, India experiences a situation in which underweight and overweight coexist in the low-SES groups. There was a slight excess of overweight women as compared with underweight women in the top wealth quintile and in groups with higher education. A strong positive relation between SES and body mass index has been found in both time points (1998-1999 and 2005-2006) and across urban and rural areas.

The analysis of the relationship between BMI and overall mortality is considered as a very crude approach of evaluating the adverse health effects of low BMI. Most of the 
studies on the the BMI and all-cause mortality have showed a U-type relationship, with mortality risks increasing at both the ends of the BMI-range. Hosegood and Campbell (2003) have conducted a longitudinal study on BMI, height, weight, arm circumference, and mortality among the rural Bangladeshi women. A J-shaped association has been found between BMI and mortality. This study has also showed that the risk of dying is the highest among women with BMI in the lowest 10 percent of the decile distribution $(<16.39)$ and the lowest among women with intermediate $(11-89 \%$ range of the decile distribution) level of BMIs.

In a study Subramanian and Smith (2006) showed that underweight was inversely related to socioeconomic status whereas socioeconomic position was positively related to being pre-overweight, overweight, and obese. The age, religion, caste, standard of living, the living environment, education, occupation, tobacco-chewing, drink, and treatment of tuberculosis has been identified as the important predictors of BMI of women.

Standard weight gain is an important indication of good health of a pregnant woman during her pregnancy. Results of a study by Islam et al. (2006) on the health status of urban pregnant women of Bangladesh with respect to BMI and weight gain have shown that the third trimester and the entire duration of pregnancy was highly significant on BMI and in both cases the gestation period has been found to be positively associated with the BMI. To deliver a healthy baby, it is very important to maintain the physical fitness of reproductive women. The aim of the study was to identify the socio-economic and demographic factors that influence the levels of physical fitness of reproductive women (aged 15-49 years) in Bangladesh.

\section{Materials and Methods}

The levels of physical fitness among reproductive women ( $n=10,996)$ were examined using the secondary data from the Bangladesh Demographic and Health Survey (BDHS) 2007 conducted and published by NIPORT (2009). Bivariate analysis was used for identifying the factors associated with physical fitness level. The fitness level was measured with BMI. To trace the determinants of physical fitness level, multinomial logistic regression analysis was adopted.

Dependent variable: The Body Mass Index (BMI) is a statistical measure of body-weight based on a person's weight and height. In recent years, the BMI has become medical standard which is used for measuring underweight, overweight, and obesity. It is a widely-used anthropometric indicator of health, especially regarding nutritional status and nutrition-related diseases. In this study, the levels of physical fitness of reproductive women based on BMI were considered as the dependent variable. There are three levels of physical fitness namely underweight, normal weight, and overweight (combining both 
overweight and obese because of very low frequency of obese women) were categorized based on the values of BMI (Table 1).

Table 1. Classification of BMI into physical fitness level.

\begin{tabular}{cc}
\hline BMI range & Classification \\
\hline$<20$ & Underweight \\
$20-25$ & Normal \\
$25-30$ & Overweight \\
$>30$ & Obese \\
\hline
\end{tabular}

Source: http://www.weightlossresources.co.uk/logout/news_features/idealweight.htm

Independent variables: Women's age, education, place of residence, currently working status, and household wealth index were considered as the independent variables.

The cross-tabulation analysis was considered as the first step in studying the association between the physical fitness level of reproductive women and some selected variables using the chi-square test of association. Moreover, in bivariate analysis, it is observable that some relationship may exist among the various factors. This individual association does not necessary to imply a causal relationship between them. Multiple regression analysis is a very useful technique for studying all the factors simultaneously. In this analysis, Multinomial logistic regression model was applied because the dependent variable under this study has more than two categories.

\section{Results and Discussion}

Women's physical fitness especially in reproductive age depends on a variety of biological, socio-economic, and demographic factors. This study was mainly concentrated on the identification of significant socio-economic and demographic factors associated with the physical fitness level. The results of chi-square test of association and multinomial logistic regression analysis has been presented in Tables 2 and 3 respectively.

From this sample profile it is clear that women's at their initial age of reproduction face more underweight or malnourished problem (about $59 \%$ of adolescent followed by $52 \%$ of women aged 20-24 years) while women at their higher ages face both the coexistence problem of underweight and overweight (about $46 \%$ underweight and $15 \%$ overweight among the women aged 40-49 years). 
Table 2. Association of physical fitness level of reproductive women with selected variables.

\begin{tabular}{|c|c|c|c|c|c|}
\hline \multirow[b]{2}{*}{ Variables } & \multicolumn{5}{|c|}{ Physical fitness level of reproductive women } \\
\hline & $\begin{array}{l}\text { Underweight } \\
\text { No.(\%) }\end{array}$ & $\begin{array}{l}\text { Overweight } \\
\text { No.(\%) }\end{array}$ & $\begin{array}{l}\text { Normal } \\
\text { weight } \\
\text { No.(\%) }\end{array}$ & Total & $\begin{array}{l}\text { Chi-square } \\
\left(\chi^{2}\right) \text { value }\end{array}$ \\
\hline \multicolumn{6}{|l|}{ Age (years) } \\
\hline $15-19$ & $781(58.8)$ & $54(4.1)$ & $493(37.1)$ & 1,328 & \\
\hline $20-24$ & $1,126(52.4)$ & $181(8.4)$ & $843(39.2)$ & 2,150 & \\
\hline $25-29$ & $859(44.9)$ & $304(15.9)$ & $752(39.3)$ & 1,915 & $283.27 * * *$ \\
\hline $30-34$ & $724(44.0)$ & $283(17.2)$ & $637(38.7)$ & 1,644 & \\
\hline $35-39$ & $671(42.5)$ & $330(20.9)$ & $576(36.5)$ & 1,577 & \\
\hline $40-49$ & $1,032(46.0)$ & $346(15.4)$ & $864(38.5)$ & 2,242 & \\
\hline \multicolumn{6}{|l|}{ Place of residence } \\
\hline Rural & $3,721(55.1)$ & $535(7.9)$ & $2495(37)$ & 6,751 & \\
\hline Urban & $1,472(35.9)$ & $963(23.5)$ & $1,670(40.7)$ & 4,105 & $653.60 * * *$ \\
\hline \multicolumn{6}{|c|}{ Women's education } \\
\hline Illiterate & $2,046(58.9)$ & $252(7.3)$ & $1,174(33.8)$ & 3,472 & \\
\hline Primary & $1,636(50.6)$ & $344(10.6)$ & $1,252(38.7)$ & 3,232 & \\
\hline Secondary & $1,350(40.9)$ & $587(17.8)$ & $1,365(41.3)$ & 3,302 & $812.87^{* * *}$ \\
\hline Higher education & $159(18.8)$ & $314(37.1)$ & $374(44.2)$ & 847 & \\
\hline \multicolumn{6}{|c|}{ Women's working status } \\
\hline Not working & $3,552(46.4)$ & $1,193(15.6)$ & $2,914(38.0)$ & 7,659 & $71.58^{* * *}$ \\
\hline $\begin{array}{l}\text { Currently } \\
\text { working }\end{array}$ & $1,640(51.4)$ & $305(9.6)$ & $1,248(39.1)$ & 3,193 & \\
\hline \multicolumn{6}{|c|}{ Women's occupation } \\
\hline Agriculture & $821(56.5)$ & $100(6.9)$ & $533(36.7)$ & 1,454 & \\
\hline Unskilled labour & $446(57)$ & $57(7.3)$ & $279(35.7)$ & 782 & \\
\hline Semiskilled & $197(42.8)$ & $71(15.4)$ & $192(41.7)$ & 460 & \\
\hline labour Business & $106(45.3)$ & $26(11.1)$ & $102(43.6)$ & 234 & $242.12 * * *$ \\
\hline Unemployed & $3,381(45.9)$ & $1,163(15.8)$ & $2,821(38.3)$ & 7,365 & \\
\hline Other & $206(54.5)$ & $27(7.1)$ & $145(38.4)$ & 378 & \\
\hline Professional & $30(17.1)$ & $53(30.3)$ & $92(52.6)$ & 175 & \\
\hline \multicolumn{6}{|l|}{ Wealth index } \\
\hline Poorest & $1,212(69.1)$ & $59(3.4)$ & $484(27.6)$ & 1,755 & \\
\hline Poorer & $1,186(60.3)$ & $82(4.2)$ & $699(35.5)$ & 1,967 & \\
\hline Middle & $1,116(53.8)$ & $145(7.0)$ & $812(39.2)$ & 2,073 & $1792.26 * * *$ \\
\hline Richer & $980(45.0)$ & $258(11.8)$ & $940(43.2)$ & 2,178 & \\
\hline Richest & $699(24.2)$ & $954(33.1)$ & $1,230(42.7)$ & 2,883 & \\
\hline
\end{tabular}

***highly significant $(\mathrm{p}=0.00)$ 
It was also found that a high prevalence of underweight problem exists in rural, illiterate, employed and the poorest women. On the other hand, a relatively high prevalence of overweight women found in urban, more educated, unemployed and the richest wealth group. Again, the chi-square test of association between physical fitness level (underweight, overweight and normal weight) and different levels of some socioeconomic and demographic variables was performed in this study. The analysis revealed that the age, place of residence, educational status, working status, occupation and wealth index category of reproductive women were significantly associated $(p=0.00)$ with their physical fitness level (Table 2).

The results of multinomial logistic regression analysis of underweight physical fitness level showed that all independent variables were the significant determinants of the women's physical fitness level, except their working status (Table 3).

It was observed that there were 39 percent of the women (aged 20-29 years) who had normal physical fitness. For this reason, we considered this age group as a reference category in multinomial logistic regression model to interpret the risk of being underweight and overweight among the women of other age-groups. The adolescent women ( $15-19$ years) were 1.31 times $(\mathrm{OR}=1.31,95 \% \mathrm{CI}: 1.15-1.51)$ more likely to be underweight or malnourished than those of aged 20-29 years with the normal physical fitness level. The women aged 30 years or above were about 20 percent less likely to be underweight $(\mathrm{OR}=0.80)$ with $\mathrm{CI}$ of $0.70-0.91$ than those women aged $20-29$ years with the normal physical fitness level. The rural women were little bit more likely $(\mathrm{OR}=1.10)$ to face underweight problem than those of urban women. The illiterate women had 2.45 times $(\mathrm{OR}=2.45,95 \% \mathrm{CI}: 1.97-3.04)$ more likely to be underweight or malnourished than the higher-educated women with the normal physical fitness status. The primary educated women had nearly double $(\mathrm{OR}=1.86)$ and the secondary educated women had about 1.6 times $(\mathrm{OR}=1.58)$ more likely to be underweight than the higher educated women of normal physical fitness level. The women having the poorest wealth index were over three times $(\mathrm{OR}=3.22,95 \% \mathrm{CI}: 2.73-3.81)$ more likely of being underweight than those of the richest wealth index having the normal physical fitness status.

Again, it was found that all the independent variables were highly significant based on the results of multinomial logistic regression analysis of overweight physical fitness level of reproductive women (Table 3). The women of 35-39 year age-group had over two times ( $\mathrm{OR}=2.13,95 \% \mathrm{CI}: 1.77-2.55)$ more likely of having overweight than those aged 20-29 years with the normal physical fitness level. The rural women were 29 percent less likely to be overweight $(\mathrm{OR}=0.71)$ with $\mathrm{CI}$ of $0.61-0.82$ than the urban women having the normal physical fitness status. The housewives were 1.55 times more likely to be overweight than the employed women of normal physical fitness at $95 \% \mathrm{CI}(1.33-1.80)$. The illiterate women were 52 percent less likely to be overweight $(\mathrm{OR}=0.48)$ with $\mathrm{CI}$ of $0.38-0.61$ than the higher-educated women of normal physical fitness. The primary and 
Table 3. Multinomial logistic regression model for physical fitness level of reproductive women.

\begin{tabular}{|c|c|c|c|c|c|c|}
\hline Logits & $\begin{array}{c}\text { Independent } \\
\text { variables }\end{array}$ & $\begin{array}{l}\text { Coefficient } \\
(\beta)\end{array}$ & $\begin{array}{c}\text { Standard } \\
\text { Error }\end{array}$ & $\begin{array}{c}\text { Significance } \\
\text { level }\end{array}$ & $\begin{array}{l}\text { Odds } \\
\text { ratio } \\
\operatorname{Exp}(\beta)\end{array}$ & $\begin{array}{l}95 \% \\
\text { confidence } \\
\text { interval for } \\
\text { odds ratio }\end{array}$ \\
\hline \multirow[t]{4}{*}{$\begin{array}{l}\text { Underw } \\
\text { eight }\end{array}$} & Intercept & -1.03 & 0.10 & 0.00 & 0.35 & NA \\
\hline & $\begin{array}{l}\text { Women's age }( \\
15-19 \\
30-34 \\
35-39 \\
40-49 \\
20-29^{(\mathrm{R})}\end{array}$ & $\begin{array}{l}\text { ears) } \\
0.27 \\
-0.21 \\
-0.19 \\
-0.20 \\
\text { NA }\end{array}$ & $\begin{array}{l}0.07 \\
0.06 \\
0.07 \\
0.06 \\
\text { NA }\end{array}$ & $\begin{array}{l}0.00 \\
0.00 \\
0.00 \\
0.00 \\
0.00\end{array}$ & $\begin{array}{c}1.31^{* * * *} \\
0.80^{* * *} \\
0.82^{* * *} \\
0.81^{* * *} \\
1\end{array}$ & $\begin{array}{c}1.15-1.51 \\
0.70-0.91 \\
0.71-0.94 \\
0.72-0.92 \\
\text { NA }\end{array}$ \\
\hline & $\begin{array}{l}\text { Women's work } \\
\text { No } \\
\text { Yes }^{(\mathrm{R})} \\
\text { Residence } \\
\text { Rural } \\
\text { Urban }^{(\mathrm{R})}\end{array}$ & $\begin{array}{c}0.02 \\
\text { NA } \\
\\
0.10 \\
\text { NA }\end{array}$ & $\begin{array}{l}0.04 \\
\text { NA } \\
0.05 \\
\text { NA }\end{array}$ & $\begin{array}{l}0.57 \\
\text { NA } \\
0.04 \\
\text { NA }\end{array}$ & $\begin{array}{c}1.02 \\
1 \\
1.10^{* *} \\
1\end{array}$ & $\begin{array}{c}0.93-1.12 \\
\text { NA } \\
1.00-1.22 \\
\text { NA }\end{array}$ \\
\hline & $\begin{array}{l}\text { Women's educ } \\
\text { Illiterate } \\
\text { Primary } \\
\text { Secondary } \\
\text { Higher } \\
\text { educated }^{(\mathrm{R})}\end{array}$ & $\begin{array}{l} \\
0.89 \\
0.62 \\
0.46 \\
\text { NA }\end{array}$ & $\begin{array}{l}0.08 \\
0.07 \\
0.07 \\
0.07 \\
\mathrm{NA}\end{array}$ & $\begin{array}{l}0.00 \\
0.00 \\
0.00 \\
0.00 \\
\text { NA }\end{array}$ & $\begin{array}{c}2.45^{* * *} \\
1.86^{* * *} \\
1.58^{* * *} \\
1 \\
3.22^{* * *} \\
2.27^{* * *} \\
1.91^{* * *} \\
1.57^{* * *} \\
1\end{array}$ & $\begin{array}{c}2.73-3.81 \\
1.95-2.65 \\
1.65-2.21 \\
1.37-1.80 \\
\text { NA }\end{array}$ \\
\hline \multirow[t]{4}{*}{ Overweighi } & Intercept & -0.53 & 0.10 & 0.00 & 0.58 & NA \\
\hline & $\begin{array}{l}\text { Women's age( } \\
15-19 \\
30-34 \\
35-39 \\
40-49 \\
20-29^{(\mathrm{R})}\end{array}$ & $\begin{array}{l}-0.99 \\
0.51 \\
0.75 \\
0.47 \\
\text { NA }\end{array}$ & $\begin{array}{l}0.15 \\
0.09 \\
0.09 \\
0.09 \\
\text { NA }\end{array}$ & $\begin{array}{l}0.00 \\
0.00 \\
0.00 \\
0.00 \\
\text { NA }\end{array}$ & $\begin{array}{c}0.36^{* * *} \\
1.68^{* * *} \\
2.13^{* * *} \\
1.60^{* * *} \\
1\end{array}$ & $\begin{array}{c}0.27-0.50 \\
1.39-2.02 \\
1.77-2.55 \\
1.34-1.91 \\
\text { NA }\end{array}$ \\
\hline & $\begin{array}{l}\text { Women's work } \\
\text { No } \\
\text { Yes }{ }^{(\mathrm{R})} \\
\text { Residence }\end{array}$ & $\begin{array}{r}\text { ig status } \\
0.44 \\
\text { NA }\end{array}$ & $\begin{array}{l}0.07 \\
\mathrm{NA}\end{array}$ & $\begin{array}{l}0.00 \\
\mathrm{NA}\end{array}$ & $\begin{array}{c}1.55^{* * *} \\
1\end{array}$ & $\begin{array}{c}1.33-1.80 \\
\text { NA }\end{array}$ \\
\hline & Rural & -0.33 & 0.07 & 0.00 & $0.71^{* * *}$ & $0.71^{* * *}$ \\
\hline
\end{tabular}


Contd.

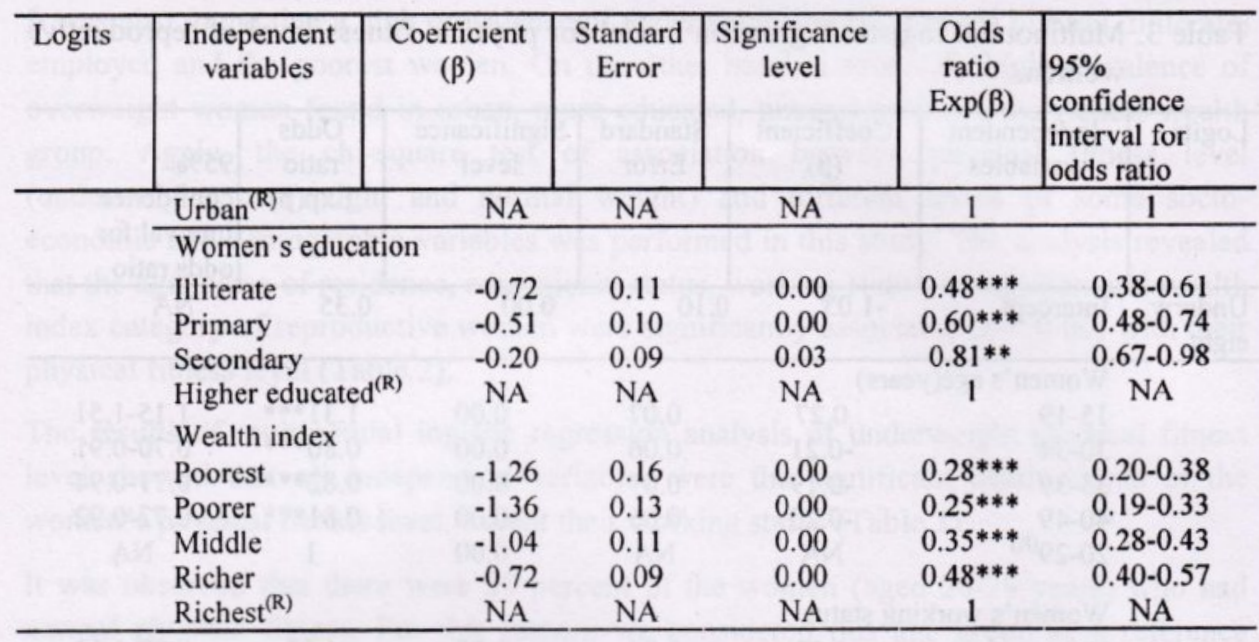

Note: The reference category is the "normal physical fitness level" of reproductive women for dependent variable; ' $R$ ' indicates reference category of the independent variables; ** significant; ***highly significant.

secondary educated women were respectively 0.60 and 0.81 times less likely to be overweight than the higher-educated women of normal physical fitness. The women having the poorest wealth index were 72 percent $(O R=0.28)$, poorer wealth index were 75 percent $(\mathrm{OR}=0.25)$, middle wealth index were 65 percent $(\mathrm{OR}=0.35)$ and richer wealth index were 52 percent $(\mathrm{OR}=0.48)$ less likely to be overweight than those of the richest wealth index with normal physical fitness respectively.

The findings of the study showed that the rate of underweight decreased with the increase in the age of women. On the other hand, the overweight problem found to be increased at the higher level of reproductive ages. The rural women were more likely to be underweight and less likely to be overweight than those of urban women. These findings support the results of Mendez et al. (2005) for developing countries. Education level was negatively associated with being underweight but positively associated with being overweight and obese. The illiterate women were more likely to face the underweight problem while higher educated women were more likely of being overweight. This picture supports the results of a research work on the reproductive women in Bangladesh (Khan and Kraemer et al. 2009). The poor socio-economic condition was found to be associated with the chronic malnutrition problem while the relatively more economically solvent women were found to have a tendency of becoming overweight. Obesity is considered a condition of high socioeconomic status in many developing countries (Caballero 2005 and Fezeu et al. 2006). 
The sample profile of this analysis revealed the coexistence of underweight and overweight problem among the reproductive women in Bangladesh that supported the findings of an. Indian study (Subramanium et al. 2009). The age, place of residence, education and the wealth index category of women were found to be significant proximate determinants of both underweight and overweight problem. The Women's working status was significantly associated with the overweight problem. To improve the physical fitness of reproductive women, some special programs are needed focusing on their proximate determinants. The findings of the study will be helpful for taking sustainable policies for reproductive women's health in Bangladesh.

\section{Limitations}

The study had two limitations. First, BMI is a crude index because it does not consider the distribution of fat, which can vary in different individuals and populations (Naser et al. 2006). Second, the results may be biased as the influence of other factors, such as smoking, physical activity, body composition, and dietary intake, was not adjusted in multinomial logistic regression.

\section{References}

Caballero, B. 2005. A nutrition paradox-underweight and obesity in developing countries. $N$ Eng $J$ Med. 352:1514- 1516.

Chhabra, P., and S.K. Chhabra. 2007. Distribution and determinants of body mass index of nonsmoking adults in Delhi, India. J Health Popul Nutr. 25:294-301.

Chiu, H.C., H.Y. Chang, L.W. Mau, T.K. Lee, and H.W. Liu. 2000. Height, weight and BMI of elderly person in Taiwan. J Germiol Med Sci 55A. M684-M690.

Fezeu, L., E. Minkoulou, B. Balkau, et al, 2006. Association between socioeconomic status and adiposity in urban Cameroon. Int J Epidemiol. 35:105-111.

Hosegood, V., and O.M.Campbell. 2003. Body mass index, height, weight, arm circumference, and mortality in ruralBangladeshi women: a 19-y longitudinal study. Am J Clin Nutr. 77:341347.

Hossain, M.G., P. Bharati, S. Aik , P.E. Lestrel, A. Abeer and T. Kamarul. 2012. Body mass index of married Bangladeshi women: trends and association with socio-demographic factors. $J$ Biosoc Sci. 44:385-399.

Islam, M.N., M.O. Ullah and M.T. Uddin. 2006. A study on health status of urban pregnant women of Bangladesh with respect to body mass index and weight gain. J Med Sci. 6:249-252.

Mendez, M.A., C.A. Monteiro and B.M. Popkin. 2005. Overweight exceeds underweight among women in most developing countries. Am J Clin Nutr. 81:714-721. 
Khan, M.M.H. and A. Kraemer. 2009. Factors associated with being underweight, overweight and obese among ever-married non-pregnant urban women in Bangladesh. Singapore Med J. 50:804.

Naser, K.A., A. Gruber and G.A. Thomson. 2006. The emerging pandemic of obesity and diabetes: are we doing enough toprevent a disaster? Int J Clin Pract. 60:1093-1097.

National Institute of Population Research and Training (NIPORT). 2009.

Subramanian, S.V. and G.D. Smith. 2006. Patterns, distribution, and determinants of under- and over nutrition: a population-based study of women in India. Am J Clin Nutr. 84:633-640.

Subramanian, S.V., J.M. Perkins and K.T. Khan. 2009. Do burdens of underweight and overweight coexist among lower socioeconomic groups in India? Am J Clin Nutr. 90:369-376.

World Health Organization (WHO). 2006. Health Organization. Obesity and overweight. Geneva: (Fact sheet no. 311). 